\title{
The Role of New Technology in Global Health Education
}

\author{
Hengameh Hosseini \\ Penn State University, Harrisburg
}

There is an intensified interest in global health issues across health related departments in colleges and universities in the United States. This has spurred the emergence of a variety of globally inclined health related programs and courses. The author of this paper developed an interdisciplinary global health course to present an overview of salient issues in global health. The course explores the many ramifications of disease, in their social, cultural, economic, political, ethical, physiological, epidemiological, and public health dimensions. A significant portion of the course is devoted to the HIVIAIDS epidemic in the developing world. The author believes the course, which has been taught once before, can be enhanced by emphasizing anthropological and cultural dimensions of healthcare, and by utilizing new media technology (Blackboard, etc.) to encourage today's technology-savvy students become more actively engaged in learning.

\section{INTRODUCTION}

The globalization process of recent decades has brought increased attention to the fact that the health of people everywhere must be a concern for all, particularly for those active in areas related to healthcare. Because of this increased attention, we have also witnessed an intensified interest in global health issues across health related departments in colleges and universities in the United States. By "global health" here, we mean "the application of the principles of public health to health problems and challenges that transcend national boundaries and to the complex array of global and local forces that affect them" (Emerson, 2001). Alternatively, global health, as defined by the United States Institute of Medicine, means "health problems, issues, and concerns that transcend national boundaries and may best be addressed by cooperative actions" (Skolnik, 2008: 8).

The above-mentioned growing concern has spurred the emergence of a variety of globally inclined health related programs and courses across institutions of higher learning in the United States, including a course on global health issues taught and developed by the author. The author sought to teach such a global course from a social science perspective, considering various dimensions of societies, including an anthropological perspective that encompasses culture. In teaching the course initially a few years ago, the emphasis on the anthropological dimensions of global healthcare, as well as the use web-based technologies, was limited. However, what I 
intend to do in this paper (and thus in my future teaching of global health) is to emphasize the anthropological / cultural dimensions of healthcare as well as the utilization of new media technology to improve my teaching of healthcare. In addition, the paper discusses why healthcare students should learn about global health, challenges of global health, methodology and implementation of the course.

\section{CULTURAL ISSUES RELEVANT TO GLOBAL HEALTH}

Cultural/anthropological issues are relevant to global health in general, and to a course in global health in particular. After all, culture - and thus anthropology - deals with human behavior. As suggested by Michal Lillis and Robert Guang Tian, "the core for anthropology as a social science is about culture and its relationship with human behavior" (2010: 99). As these authors suggest: "More specifically, culture consist of traditional values and beliefs, idea, customs, skills, arts and language of a specific group in a given period. Culture provides people with a sense of identity and an understanding of acceptable behavior in the society. In the twentieth century, culture emerged as a concept central to anthropology encompassing all human phenomena that are not purely results of human genetics" (Ibid).

According to Lillis and Tian, "for anthropologists, culture is the integrated system of socially acquired values, beliefs and rules of conduct which delimit the range of accepted behavior in a given society. Cultural differences distinguish societies from one another" (Ibid: 100). In future offerings of the course, the author intends to emphasize more strongly, and devote greater time to the significance of culture/anthropology in understanding global health. Culture can be viewed as an important determinant of health in various societies, in several ways that include the following:

- Culture in any society is connected to health behaviors in that society. For example, people's attitudes about food are related to culture, and attitudes about food can affect hygiene practices of people, pregnancy, the length of time women breastfeed, etc. In fact, culture affects all types of hygiene practices of members of a society.

- Culture influences the way people perceive illness. Different culture groups have different beliefs about what constitutes good health and what constitutes illness and diseases.

- Culture influences the extent to which people use health services. For instance, while in some societies individuals seek health services as soon as they feel sick, in other societies, people may only seek the utilization of health services when severely ill.

- Finally, it can be said that different cultures of the world have different practices that concern health and medical treatment. In terms of global health, this suggests the significance of medical anthropology which is the study of how cultural, ecological, societal and historical forces impact the medicine used in each society, as well as how these forces impact individual health, the health of particular communities, and environmental stability in various regions. Studying medical anthropology can increase understanding of health-related beliefs and behaviors, from the products of medical and scientific research, to culturally-scripted healing rituals. 


\section{WHY SHOULD HEALTHCARE STUDENTS LEARN ABOUT GLOBAL HEALTH?}

There are many reasons students need to know and learn about global health. Among them: Diseases do not respect national boundaries. In Richard Skolnik's book, Essentials of Global Health (2008), we read: "Human Immunodeficiency Virus (HIV) has spread worldwide. A person with tuberculosis can infect 15 people a year, wherever they are...In addition, there is an important risk of a worldwide epidemic of influenza". Clearly the health of each of us increasingly depends on the health of others.

- In an increasingly global and interconnected world, health issues are connected to economic and social development. Malnourished children may not realize their full intellectual potential, or even be able to finish school. Such sick children, mostly residing in poorer countries, are less likely to become productive adults who contribute to the economic well-being of their family, community or country. Adults who suffer from AIDS, tuberculosis, malaria, and other diseases lose their source of livelihood, causing an endless cycle of poverty. All of those will definitely have global economic consequences (in terms of the need for global economic assistance, legal/illegal immigration, etc.).

- There is an ethical dimension to this global problem. As people with a sense of justice, students should be concerned that children in poor countries die needlessly from malnutrition or preventable diseases, or adults die prematurely for lack of access to medicines readily available in the developed world.

- These and other factors have caused an increasing interest in various universities in studying health from a global perspective. In fact, many institutions of higher learning in the United States have launched programs in global health offering relevant courses. Among the most prominent are the University of North Carolina at Chapel Hill's Gillings School of Global Public Health, Harvard University's Initiative for Global Health Institute, and John's Hopkins' Center for Global Health.

In recent decades, it has become apparent that health problems are more effectively studied from a global perspective than from the point of view of any individual country. As suggested by Merson, Black, and Mills (2001), the very term "global health" suggests that countries must work together not only to understand critical health issues, but also to solve them. According to Aaronson, Counter, and Ramirez, global health has also become a concern of educators of Healthcare Management: "We can no longer teach healthcare management with the implicit assumption that all health care is local. With digitization and increased movement of patients and professionals across national borders, all healthcare services must operate in a global marketplace" (Aaronson et al. 2008: 187). According to those writers, agencies that deal with healthcare education, i.e. agencies such as The Association of University Programs in Health Administration (AUPHA) and Commission on Accreditation of Health Management Education (CAHME) must also be concerned with global health issues. In their own words, these agencies must ensure that "students graduated from AUPHA member and accredited programs are globally competent and prepared to work in a globalized health service industry" (ibid: 187).

The United Nations too has recognized the importance of global health issues. This recognition by the United Nations is evident in the Millennium Development Goals which were formulated during the UN's Millennium Summit 2000. Out of the 15 core targets that countries signed and pledged to meet by 2015, eight relate to global health (UN Millennium Project Goals, 2006). These eight goals are: (1) Eradicate extreme hunger and poverty, (2) Achieve universal 
primary education, (3) Promote gender equality and empower women, (4) Reduce child mortality, (5) Improve maternal health, (6) Combat HIV/AIDS, malaria, and other diseases, (7) Achieve environmental sustainability, and (8) Develop a global partnership for development.

While a few of the Millennium Development Goals directly concern health, such as reducing child mortality, the other goals relate to health indirectly. For example, hunger and poverty can be viewed as both a cause of disease as well as a consequence of bad health. Universal primary education can only be achieved if children enjoy sufficiently good health to attend school and retain lessons. In addition, gender empowerment can lead to better access to health care for women, and lack of safe water and sanitation can cause ill health. In fact, many studies have demonstrated the importance of environmental issues to global health, arguing that environmental health issues are major risk factors in the global burden of disease. One such study is the one conducted by Lopez, Mathers, and Murray in 2006. According to this study, about $8.6 \%$ of the total burden of disease in low and middle income countries can be attributed to three general environmental factors of: unsafe water, hygiene, and excreta disposal; urban air pollution; and indoor smoke from household use of solid fuels. In a previous study Smith, Carvalan, and Kjellstom (1999) demonstrated that environmental risk factors can explain somewhere between 25 and 33 percent of the global burden of disease.

In a course about global health, we can examine the most critical global issues discussed above, such as those pertaining to HIV/AIDS epidemic. In such a course, we can provide students of health care with an overview of the importance of global health, and examine the most important global health issues and their economic and social consequences.

Although all diseases should be the concern of students of health care, particularly if they are globally inclined, HIV/AIDS demands particular attention. For, Skolnik (2008: 192) writes, "Human Immunodeficiency Virus (HIV) and Acquired Immune Deficiency Syndrome (AIDS) can justifiably be considered the plague of the 21 th century. Rarely has a single pathogen have a greater impact on the human condition than HIV".

\section{CHALLENGES OF GLOBAL HEALTH}

This course was initially designed and taught (once before) because of the belief that students of health care should care should be familiar with one of the guiding philosophies of the World Health Organization. Namely, "health" encompasses a complete physical, mental and social well-being, and that "enjoyment of the highest attainable standards of health is one of the fundamental rights of every human being without distinction of race, religion, and political belief, economic and social conditions" (World Health Organizations Reports, 2009).

Despite the many health-related challenges that various countries face today, it is an undeniable fact that significant progress has been made in the improvement of the health of their populations during the last few decades. For example, the death rate of children under five years has fallen from 148 deaths per 1000 children to fewer than 60 deaths per 1000 children. During the same decades, according to Levine (2007), the average life expectancy in less advanced countries has improved, increasing from 40 years to 65 years. In the meantime, "smallpox has been eradicated, polio has nearly been eliminated, and great progress has been made in reducing the burden of vaccine- preventable diseases in children and parasitic infections, such as Guineas worm" (Skolnik, 2008). Of course, because of poverty and other related reasons many challenges remain (see the box below). 


\section{BOX 1. CHALLENGES REMAINED}

- 10,000 babies die every day in the world before they are four weeks old (WHO Reports, 2006)

- 529,000 women a year die (in the world) during childbirth (WHO Reports, 2006)

- More than 750,000 children die every year (in the world) of measles (Matters, Lopez, and Murray, 2001)

- 1.6 million people die in the world every year of TB (Skolnik, 2008)

- According to Lopez, Matters, Ezzati, et al. (2006), infections of the respiratory tract and middle ear are major causes of infant and child mortality. Mortality in tuberculosis has increased due to the spread of HIV.

- Diarrheal infections are responsible for 17 percent of deaths among children under the age of five worldwide, the second most common causes of child death globally. According to WHO (2007), hygienic measures alone are insufficient for the prevention of diarrhea. Vaccines are also needed.

- According to Hoffman (2009: 236), malaria kills over one million people annually, $90 \%$ of them children under the age of five.

- Deaths from malaria, transmitted via mosquito bites, can be easily reduced by the use of insecticide-treated bed nets and other measures. However, according to WHO (2005), only $23 \%$ of children and $27 \%$ of pregnant women in Africa were estimated to have access to nets.

- In a 2005 Declaration, African heads of state claimed that malaria had depressed income growth in Sub-Saharan Africa so much since the 60s that GDP in the region today is 40 percent lower (Bleakley, 2009: 218). According to Bleakley, malaria and hookworm explain a nontrivial amount of income difference between temperate and tropical areas (ibid: 223).

- According to WHO (2006), more than two billion people in the world are at the risk of micronutrient deficiencies (including lack of vitamin A, iron, iodine and zinc). Among children under the age of five in the developing world, malnutrition is a factor in 53\% of death associated with infectious diseases.

Why should these bleak statistics concern to students living in industrialized countries? Even ignoring ethical reasons for it, we can emphasize that, diseases do not respect national boundaries. For example, tuberculosis, HIV, and polio can spread from one country to the next very easily. According to Skolnik (2008), cases of dengue fever, an infectious disease of the topics transmitted by mosquitoes and characterized by rash and aching head and joints, which was once largely restricted to Southeast Asia, are now found in many more countries outside the region. The same can be said of avian flu, Swine flu and other such diseases. There exist other global challenges as well. One can speak of disparities in the health among nations. Because of such disparities, in 2006 life expectancy in Japan was 82 years, while in Haiti it was only 52. As a result of income disparities across the globe there exit numerous life saving technologies and medical interventions, such as the Hepatitis B vaccine, that are being used in rich counties, or the rich among poor counties, to which most people in low-income nations lack access. As concerned human beings, we cannot be indifferent to such disparities about health (Levine, 
2007). As Martin Luther King, Jr. stated, "Of all forms of inequities, injustice in healthcare is the most shocking and inhumane."

\section{IMPLEMENTING THE COURSE: METHODOLOGY}

The author taught this course once before, however, without emphasizing the utilization of new technology. In this global health course, she taught fourteen students majoring in Biology, PA (Physician Assistant), Business Administration, Accounting, and Sport Medicine (Training). Students were required to participate in several activities. About half of the class time was devoted to lecturing on various dimensions of global health. However, prior to my lectures, students were expected to spend about ten minutes collectively reporting the current global events relevant to class topics, and participate in another ten minutes' worth of class discussion about issues raised in the reports or any related topics of interest. Of course, to encourage class discussion, students' opinions were also sought during my lectures. Throughout the semester, I also showed several videos that expanded on global health topics presented in lectures. The videos shown include: Typhoid Mary: The Most Dangerous Woman in America; Bird Flu: How Safe Are We? Disease Warriors: Rise of the Superbugs; Delivering the Goods: Deadly Messengers; Back to the Basics: How Safe Are We? And Ebola: The Plague Fighters.

In addition to two in-class exams, students were given other assignments: They were to read cases about global health to be discussed in class, summarize text chapters, and write and present a formal research paper in class. The student paper and its methodology constituted a means of making the course innovative. For the paper, viewed as a global research initiative, students were expected to apply qualitative research methodology. After all, as suggested by Ann Bowling, "qualitative research method is the main method used by anthropologists in participant observations and /or qualitative interviewing of members of culture (ethnography), and by social scientists whose approach is rooted in a phenomenological perspective." (1997: 312).

Qualitative research techniques can also be utilized in health care research. For example, qualitative research can be used in research documenting the experience of chronic illness. On the other hand, the qualitative investigator has the advantage of getting close to the research material, and can obtain a great deal of in-depth information that can be tested (Ibid).

These papers were based on their research, which consisted of their interviews of various physicians, nurses, students, professors and other individuals born and raised in other countries in particular, poor/less developed countries. The interviews conducted by students themselves and later served as the basis for their papers, were to address global health and its management, and to focus preferably on less-developed countries. At the end of semester, students presented the results of their research in class, to benefit their fellow students. Examples of these papers written by students were: (1) Women in Sub-Sahara Africa: Why is the Incidence of HIV/AIDS High Among them? Uganda and HIV/AIDS Epidemic: A Success Story? And Is Typhoid the Most Communicable Disease in India?

For various reasons, I believe, the course was a success. For one thing, I received a score of 4.97 (out of a maximum of 5) on student evaluations. I also received very enthusiastic feedback from students about the subject matter covered and non-standard format and assignments of the course. The positive reception was also obvious in the written comments of student evaluations.

I believe the success of the course was also evident based on the pre and posttest /surveys I gave to my students in that class. This (i.e. pre-posttests) consisted of a serious of questions I gave to students at the beginning and at the end of the semester. On the basis of this pre and post 
test assessment, I am able to state that the course was very successful, since a great deal of learning took place, as was evident when comparing the responses to the very same questions that appeared in both of those two assessments. The author believes that the utilization of new information technology, which would be utilized in the future teachings of this course, can enhance this course even further.

\section{WHAT ISSUES WERE COVERED IN THE COURSE?}

The primary objective of the course was to make students familiar with the following:

- The determinants of health

- The measurement of health status

- The importance of culture to health

- The global burden of disease

- The key risk factors for different health conditions

- Global demographic and epidemiologic transitions

- The organization and functions of health systems

TABLE 1

PRIMARY LEARNING OBJECTIVES OF THE COURSE

\begin{tabular}{|c|c|}
\hline Section & Specifics \\
\hline Section 1: Principles of Global Health & $\begin{array}{l}\text { A. Key principles and goals } \\
\text { B. Determinants of global health } \\
\text { C. Healthcare and degree of development }\end{array}$ \\
\hline Section 2: Themes of Global Health & $\begin{array}{l}\text { A. Health and ethics } \\
\text { B. Organization of healthcare systems } \\
\text { C. Culture and global health }\end{array}$ \\
\hline $\begin{array}{l}\text { Section 3: Causes of Illness and Diseases } \\
\text { Across the Globe }\end{array}$ & $\begin{array}{l}\text { A. Health and environment } \\
\text { B. Nutrition and health issues } \\
\text { C. Reproductive health } \\
\text { D. Child healthcare } \\
\text { E. Communicable diseases } \\
\text { F. Non-communicable diseases } \\
\text { G. Unintentional injuries }\end{array}$ \\
\hline $\begin{array}{l}\text { Section 4: Working Together to Improve } \\
\text { Global Health }\end{array}$ & $\begin{array}{l}\text { A. Impact of wars, ethnic conflict, and } \\
\text { natural disasters on global health } \\
\text { B. Global actors in healthcare } \\
\text { C. Science, technology, and healthcare }\end{array}$ \\
\hline $\begin{array}{l}\text { Section 5: Emphasizing other Factors in the } \\
\text { Course }\end{array}$ & $\begin{array}{l}\text { A. Effective writing } \\
\text { B. Critical thinking } \\
\text { C. Effective oral communication }\end{array}$ \\
\hline
\end{tabular}

In addition, I strove to ensure that the students understood the connections that exist between health and education and among health, equity, poverty and the degree of economic development 
in each country. Students were also to learn how different health issues, including nutrition, reproductive health, child health, infectious diseases, non-communicative diseases, injuries, and environmental health, affect people on national, regional, and global scales. To achieve those goals, the course was structured to include some four sections. The following table summarizes the four sections, as well a fifth section that includes competencies related to the course.

In order to make students familiar with the principles of global health, they were introduced to the following: key principles, themes and goals of health across the globe; how to investigate the various determinants of health, the way health is measured, and how health conditions change over time as countries become more advanced economically; and the connections that exist between health and the degree of economic development across the globe, including connections between health and education, and between health and economic equity and poverty.

In the second section of the course that focused on the themes of global health, students were introduced to three types of issues. First, the instructor made sure that students would learn how health, human rights and ethical issues are connected across the globe. Second, students learned how various countries have organized their health systems, the challenges that health systems face in different countries, the consequences and costs of these challenges, and how different countries respond to these challenges and their consequences. In the last part of this section of the course, students were introduced to the following: the connection that exists between culture and health across the globe and emphasizing the importance of culture to health, and how various cultural groups within culturally diverse nations view health, engage in health practices, and promote health behavior. This last issue has particular relevance to the way HIV/AIDS spreads and is prevented in various countries across the globe.

In the third section of the course, students were introduced to the various causes of illness, disability, and health, particularly as these relate to low and middle-income countries of the world. Specifically, this section dealt with the following issues: environmental factors as they relate to health across the globe; nutrition and its impact on health across the globe; reproductive health across the globe; communicable diseases and their challenge across the globe, paying particular attention to the spread of HIV/AIDS; and, finally, unintentional injuries across the globe.

Section four of the course, entitled "Working Together to Improve Global Health", introduced students to the following. First, students learned the impact that ethnic conflicts and wars, and natural and other types of disasters have on global health. Second, students were provided with an overview of how various global actors such as the United Nations, individual governments, and nongovernmental/charity organizations can and do work individually or cooperatively to address key global health problems and concerns. Finally, students were introduced to how science and technology can help to improve health in various nations, as well the potential for further advances in this type of science and technology to improve global heath in the future.

The text for the course was Essentials of Global Health by Richard Skolnik; students were also supposed to read essays from Global Health and Global Aging, edited by Mary Robinson. Both of these global heath texts were both global and interdisciplinary. The text by Skolnik also pays particular attention to the links among poverty, degree of economic development, and health; between health and equity; and between gender, ethnicity, well-being and health.

The fifth section of the above table is the summary of the competencies related to the course, since the course was designed to also emphasize competencies in writing, critical thinking, and oral communication. Those competencies can be described as follows. (A) Effective Writing. In 
the course, students were expected to apply the principles of effective writing to specific questions and problems that related the social sciences to global healthcare. In assessing the writing competency on the part of students, we used the following criteria: if their writing was well organized and rhetorically effective; if their presentations were clear and concise; and if effective social science vocabulary was being used. (B) Critical Thinking. For that, students were expected to effectively: apply health/social science theories to the problems of global health; and apply the scientific method in their analysis of global health. Students were also expected to correctly identify the problems of global health, apply relevant principles, choose and defend appropriate decisions regarding their recommended policy strategy, and draw appropriate conclusions and make recommendations consistent with the theory and data presented and analyzed. (C) Effective Oral Communication. In the course, students were expected to apply effective speaking principles and techniques in their arguments/presentations that related the social sciences to global health. That required the following criteria: appropriate delivery of oral presentations, written reports, and other assignments, demonstrating mastery of the topic; clear definition of the issues and problems and clear communication of the purpose of the report; expressing conclusions clearly and in an organized manner; and relating his/her paper/report to others those of others in class.

\section{UTILIZING NEW MEDIA TECHNOLOGY IN TEACHING GLOBAL HEALTH}

As stated above, I taught Global Health once before, utilizing very little technology in my teaching it. Since my teaching of Global Health several years ago, I have become convinced of the value of the utilization of web-based new technology for my teaching of it in the future. Based on my own teaching of both on-campus and online graduate level healthcare administration courses, I am convinced that the integration of new web-based technology can enhance student learning. My positive experience with the utilization of web-based technology has been substantiated by various studies. In fact, various individuals in the academia and the corporate world have become connived of the value of this contribution. For example, in 2008, the Economist's Intelligence Unit, in a study entitled "The future of Higher Education: How Technology Will Shape Learning", executed a survey of 189 academicians and 100 persons from the corporate world to predict the role, and the impact and value of new technology in higher education. In fact, some $2 / 3$ of those 289 individuals believed that new (web-based) technology has had - and will continue to have - a significant impact on higher education, that this technology will have a positive role in teaching-learning that takes place in the institutions of higher learning... May other researchers/writers too are convinced of the positive role that new web-based technology can and will have in academia's learning and teaching activities. Such writers include Manuel Castells, Dennis Sparts, Kathleen Fulton, and others.

As a result of author's own experience and the above-mentioned studies, the she is convinced that by integrating new technologies into this global health course, students can attain more information, and can become more engaged; each of the technologies utilized will enhance coordination, and communication needed to achieve the above objectives of the course. Additional benefits of the utilization of new technology can include: making distance learning more equitable; much easier dissemination of information; facilitating collaboration among participating students; enhancing motivation for learning among computer-savvy students; and helping students with greater flexibility and independence for acquiring their own knowledge. Students can meet the needed competencies and objectives for the course if the author utilizes 
Blogs, Wikis, Second Life, Skype and other new technologies. In fact, one of the challenges faced by those of us in the academia today, including in health-related fields, is to meet the requirements of computer-savvy, internet oriented students. Utilization of these new media technologies will facilitate much of what is needed- providing necessary information, causing student active engagement, etc.

Among those new media technologies is Wikis. Wikis can be used in the learning process, including information that concerns global health; it is a web communication and collaboration tool that can be utilized in this global course in order to engage students in learning with others within collaborative environments. Each student in this type of collaborative environment can share with fellow students what he/she has learned about global health. He/she can also learn from fellow students in these collaborative environments.

The author's teaching of global health can also be enhanced by utilization of Blogs. Through this medium, students can leave comments and messages that concern global health, thus creating a great of interaction between and among my students and myself. The ability of my students, as readers, to leave comments about their views of, or newly found information about, global health issues provides a very interactive format which enhances the learning process in my teaching of global health.

The author's teaching of global health issues can also be enhanced by utilization of Second Life, which is a Web-Based multi-user 3D virtual world developed by Linden Lab in 2003. Since its inception in 2003, Second Life has become one of the most popular virtual reality tools, particularly by academicians who wish to provide opportunity for interaction among students and faculty, and a sense of community. In fact, many institutions of higher learning are utilizing Second Life in their teaching, particularly in their online classes. It is possible to integrate Second Life with web 2.00 tools such as Wikis and Blogs.

My discussion of global issues can also be enhanced by the use of Skype, allowing students to also learn from fellow students more directly.

\section{CONCLUDING REMARKS}

One of the foremost global challenges faced today is global health. For various reasons, the health of people everywhere must be a growing concern for those involved in the study and practice of health care. This explains the emergence of courses dealing with global health in recent years, and the proliferation of research and writing in areas that relate to the study and practice of global health care. The course the author designed and taught is a response to this growing concern. Since the study and practice of global health requires an understanding of the various dimensions of global health, effort was made to consider global health from various social science perspectives. Also, because the challenges of global health relate to poverty, underdevelopment, and malnutrition, an attempt was made to emphasize the health problems of poorer countries. The challenges of poor nations were also addressed in the research component of the course, for which students were expected to write a paper on global health on the basis of their interviews (i.e., qualitative research) of health professionals and students raised in such countries. Again, as suggested above my global health course can be enhanced by the utilization of new media technology.

One may wonder if this course met its objectives, thus, students learned what I had desired for them to learn about global heath. Based on various assessments in the course, this author truly became convinced that the course was very successful achieving its goals and objectives. 
Because of this course, I am convinced that students were able to understand the connections that exist between health, education, and in particular among health, equity, poverty, and the degree of economic development of each country. Additionally, in author's view, utilization of new technologies will lead to even more learning of global health issues. How was the degree of success measured and based on what evidence? Success in my global healthcare course was evident in three different ways. (1) Utilizing qualitative research techniques in their interviews of various physicians, nurses, and other healthcare professionals born and raised in counties other than the United States, my students in that global healthcare course wrote and presented very informative papers describing healthcare problems, issues and challenges faced by various countries, in particular those in the developing world. (2) In response to various questions about global health I asked for mid-term and final examinations, students demonstrated a thorough understanding of the healthcare issues and concerns of the global community. (3) The learning that took place in that global healthcare course was also evident in the comparison of the responses of students to the same questions I gave in the pre and post assessment tests for the course. As these three measures indicated, students learned a great deal about global health in that class.

\section{REFERENCES}

Aaronson, W.E., Counte, M., Ramirez, B. (2008). A Comparative Perspective on Contemporary Trends in Global Healthcare Management Education. Journal of Healthcare Administration Education, 25(3), 175-190.

Black, R.E., Morris, S.S., \& Bryce, J. (2003). Where and why are 10 million children dying every year? The Lancet, 361(9376), 2226-2234.

Bleakley, H. (2009). Economic effects of childhood exposure to tropical disease. American Economic Review, 99(2), 218-223.

Bowling, A., (1997). Research methods in health: Investigating health and health services, Open University Press.

Edberg, M. (2007). Essentials for health behavior. Sudbury, MA: Jones and Bartlett Publishers.

Economist's Intelligence Unit (2008). The future of higher education: How technology will shape learning, published by the Economist's Intelligence Unit.

Fenner, F., Henderson, D. A., Arita, I., Jezek, Z., \& Ladnyi, I. D. (1988). Smallpox and its eradication. Geneva: World Health Organization.

Hobcraft, J. (1993). Women's education, children's welfare and child survival: A review of the evidence. Health Transition Review, 3(2), 159-173

Hoffman, V. (2009). Intrahousehold allocation of free and purchased mosquito nets. American Review of Economics, 99(2), 236-241. 
Institute of Medicine (1998). America's Vital Interest in Global Health. Washington, DC:

National Academy Press.

Jamison, D.T., Breman, J.G., Measham, A.R., Alleyne, G., Claeson, M., Evans, D.B., et al. (Eds.). (2006). Disease Control Priorities in Developing Countries, New York, Oxford University Press.

Levine, R. (2007). Case studies in global health: Millions saved. Sudbury, MA: Jones and Bartlett Publishers.

Lillis, M.P. and Tian, R.G. (2010). Cultural Issues in the Business World: An anthropological Perspective, Journal of Social Sciences, 6(1), 99-112.

Lopez, A.D., Matters, C.D., Ezzati, M., Jamison, D.T., \& Murray, C.L. (2006). Global burden of disease and risk factors. New York: Oxford University Press.

Mann, J.M., Gostin, L., Gruskin, S., Brennan, T., Lazzarini, Z., \& Fineberg, H.V. (1994). Health and human rights. Health and Human Rights, 1(1), 6-23

Matters, C.D., Lopez, A.D., Murray, C.J.L. (2001). The burden of disease and mortality by condition: Data, methods, and results for 2001. In A.D. Lopez, C.D. Mathers, M. Ezzati, D.T. Jamison, \& C.J.L. Murray. Global Burden of Disease and Risk Factors (pp. 45-93). New York: Oxford University Press.

Merson, M.H., Black, R.E., Mills, A.J. (2001). International public health: Diseases, programs, systems, and policies. Gaithersbug, MD: Aspen Publishers.

Murphy, E. (2005). Promoting healthy behavior. Health Bulletin 2. Washington, D.C.:

Population Reference Bureau.

Roberts, M. (2005, July 03). How doctors killed off smallpox. BBC News Online. Retrieved from http://news.bbc.co.uk/nolpda/ifs_news/hi/newsid_4072000/4072392.stm

Robinson, M., Novelli, W., Pearson, C., Norris, L. (Eds.). (2007). Global health and global aging. New York: Jossey-Bass.

Rosen, S., Sanne, I., Collier, A., \& Simon, J.L. (2005). Hard choices: rationing antiretroviral therapy for HIV/AIDS in Africa. Lancet, 365(9456), 354-356.

Ruger, J.P., Jamison, D. T., Bloom, D.E., Canning, D. (2001). Health and economy. In M.H. Merson, R.E. Black, \& A.J. Mills. (Eds). International public health diseases, programs, systems and policies (pp. 219-223). Gaithersburg, MD: Aspen.

Shekar, M., Heaver, R., Lee, Y. \& The World Bank (Eds). (2006). Repositioning nutrition as central to development: A strategy for large-scale action. Washington, D.C.: World Bank Publications. 
Skolnik, R. (2008). Essentials of global health. Boston: Jones and Bartlett Publishers.

Smith, KR, Corvalan, C., Kjellstrom, T. (1999). How much global ill-health is attributable to environmental factors. Epidemiology, 10(5), 573-584.

United Nations Millennium Project: Goals, targets, and indicators. (2006). Retrieved from http://www.unmillenniumproject.org/goals/gti.htm

The World Health Organization World Health Reports (1995-2009). Retrieved from http://www.who.int/whr/previous/en/

The author wishes to thank the editors and the reviewers of IJBA for their very constructive comments in helping revise the paper. 